\title{
Uma Medicina do Esporte cada vez mais forte
}

Está chegando ao fim a gestão da diretoria comandada pelo Dr. Marcelo Salazar de Veiga Pessoa. Será eleita no Congresso de Brasília a diretoria a ser comandada pelo Dr. Marcos Aurélio Brazão de Oliveira, já eleito em 1997 para assumir a presidência da SBME neste ano. As diferentes diretorias da Sociedade Brasileira de Medicina do Esporte trabalharam até hoje, cada uma com as suas características e méritos, com pelo menos um objetivo comum: o de fazer com que a nossa especialidade se torne cada vez mais forte. Uma especialidade forte deve contar entre outros aspectos com uma publicação científica expressiva. Desta forma, lutar por uma Medicina do Esporte no Brasil significa também trabalhar para fortalecer a Revista Brasileira de Medicina do Esporte.

Nesses anos de sua breve existência, a Revista Brasileira de Medicina do Esporte consolidou-se como o mais expressivo instrumento científico na área de Medicina do Esporte no nosso país.

A evolução da RBME pode ser medida em números: em 1995, o número de páginas de texto científico foi de 140; em 1996, tivemos 105 páginas; em 1997, foram 143; em 1998, já com a Revista bimestral e com periodicidade regular, foram 254 páginas; para 1999 a perspectiva é de um número ainda maior.

Ademais da questão meramente numérica, tivemos o prazer de contar com artigos escritos especialmente para nós por algumas das maiores autoridades internacionais na nossa especialidade: Dr. Eduardo Henrique De Rose, presidente da Federação Internacional de Medicina do Esporte; Dr. Carlos Pablo D'Angelo, presidente da Confederação Panamericana de Medicina do Esporte; Dr. Walter Frontera, chefe do Serviço de Medicina Física e Reabilitação do Hospital da Faculdade de Medicina da Universidade de Harvard, Boston, Estados Unidos; Prof. William (Bill) Ross, canadense, uma das maiores autoridades na área de cineantropometria; Dr. Per Renström, do Serviço de Ortopedia do Instituto Karolinska, Estocolmo, Suécia; Dr. Thomas Rowland, do Baystate Medical Center, Springfield, Massachusetts, Estados Unidos, uma das maiores autoridades na área de exercício em pediatria; Dr. Lyle Micheli, da Divisão de Medicina do Esporte do Children's Hospital de Boston, Massachusetts, Estados Unidos. Contribuíram também muitas das maiores autoridades no Brasil na nossa especialidade.

Contamos ainda com documentos da Federação Internacional de Medicina do Esporte, do Colégio Americano de Medicina do Esporte e da Confederação Panamericana de Medicina do Esporte, traduzidos com permissão; além do intercâmbio firmado com a revista espanhola Archivos de Medicina del Deporte, umas das mais expressivas publicações européias.

Recebemos também uma solicitação de permissão para republicação na Medicine and Science in Sports and Exercise (órgão oficial do Colégio Americano de Medicina do Esporte) de abstracts selecionados de artigos publicados na RBME.

Um outro fato concreto que atesta o crescimento científico da RBME e que nos deixa muito satisfeitos é que alguns dos mais expressivos grupos de pesquisa em Medicina do Exercício e do Esporte e Ciências do Esporte têm feito da RBME o veículo para publicação da sua produção científica.

Sempre se corre o risco de injustiças ao se citar nomes, mas sem dúvida, entre os atuantes colegas do Conselho Editorial, merecem destaque pelo interesse e pelas valiosas contribuições os colegas Antonio Claudio Lucas da Nóbrega, Arnaldo José Hernandez, Eduardo Henrique De Rose, Flávia Meyer e Marcos Aurélio Brazão de Oliveira. Entretanto, é sempre importante lembrar que o sucesso da RBME deve ser creditado ao esforço de vários dos colegas em todo o país que deram as suas contribuições e também ao competentíssimo trabalho realizado pela equipe da Redprint Editora, comandada pelo Sr. Tadaharu Katayama. O trabalho desta equipe se caracteriza - entre outros aspectos - pelo perfeccionismo, conhecimento técnico e seriedade.

Desta forma, contando com o trabalho, o engajamento e o interesse concreto de colegas de todo o Brasil e partindo do trabalho já realizado pelas diretorias anteriores da SBME, incluindo a atual - podemos de modo realista enxergar horizontes cada vez mais amplos na próxima gestão para a SBME e a sua publicação oficial, a RBME.

\author{
José Kawazoe Lazzoli \\ Editor-Chefe, \\ Revista Brasileira de Medicina do Esporte
}

